\title{
Microsurgical anatomy of the central lobe
}

\author{
Thomas Frigeri, MD, ${ }^{1}$ Eliseu Paglioli, MD, PhD, ${ }^{2}$ Evandro de Oliveira, MD, PhD, ${ }^{3}$ \\ and Albert L. Rhoton Jr., MD'

\begin{abstract}
1Department of Neurological Surgery, University of Florida, Gainesville, Florida; ${ }^{2}$ Department of Neurosurgery, Pontificia Universidade Catolica do Rio Grande do Sul, Porto Alegre; and ${ }^{3}$ Department of Neurosurgery, Instituto de Ciências Neurológicas, São Paulo, Brazil
\end{abstract}

\begin{abstract}
OBJECT The central lobe consists of the pre- and postcentral gyri on the lateral surface and the paracentral lobule on the medial surface and corresponds to the sensorimotor cortex. The objective of the present study was to define the neural features, craniometric relationships, arterial supply, and venous drainage of the central lobe.

METHODS Cadaveric hemispheres dissected using microsurgical techniques provided the material for this study. RESULTS The coronal suture is closer to the precentral gyrus and central sulcus at its lower rather than at its upper end, but they are closest at a point near where the superior temporal line crosses the coronal suture. The arterial supply of the lower two-thirds of the lateral surface of the central lobe was from the central, precentral, and anterior parietal branches that arose predominantly from the superior trunk of the middle cerebral artery. The medial surface and the superior third of the lateral surface were supplied by the posterior interior frontal, paracentral, and superior parietal branches of the pericallosal and callosomarginal arteries. The venous drainage of the superior two-thirds of the lateral surface and the central lobe on the medial surface was predominantly through the superior sagittal sinus, and the inferior third of the lateral surface was predominantly through the superficial sylvian veins to the sphenoparietal sinus or the vein of Labbé to the transverse sinus.
\end{abstract}

CONCLUSIONS The pre- and postcentral gyri and paracentral lobule have a morphological and functional anatomy that differentiates them from the remainder of their respective lobes and are considered by many as a single lobe. An understanding of the anatomical relationships of the central lobe can be useful in preoperative planning and in establishing reliable intraoperative landmarks.

http://thejns.org/doi/abs/10.3171/2014.11.JNS14315

KEY WORDS central lobe; cerebral arteries; cerebral veins; craniometrics; gyrus; microsurgical anatomy; sulcus

$\mathrm{T}$ HE central lobe, composed of the pre- and postcentral gyri and the paracentral lobule is one of the most eloquent areas of the brain, and it corresponds to the sensorimotor cortex. This morphological unit, together with the functional interaction between motricity and sensitivity, justifies the characterization of these gyri as a single lobe. ${ }^{45}$

There have been several studies of gyral and sulcal anatomy, craniometrics, and vascular features that included this area. 1,4,10,11,17,19,21-24,28,36,39-41,43-46,51,54,56,57 However, important details are still lacking. The aim of the present study is to define the neural features, craniometric relationships, arterial supply, and venous drainage of the central lobe.

\section{Methods}

The central lobe was examined under magnifications of $\times 3$ to $\times 40$ in 20 formalin-fixed cadaveric hemispheres in which the arteries were perfused with red and the veins with blue silicone. The frontal and parietal bones were removed while preserving the coronal suture to study its relationship with the anterior and posterior limits of the precentral gyrus. The arachnoid membrane was removed from the gyral surfaces and variations in the sulci and gyri were examined. The inclination of the central sulcus and coronal suture compared with their coronal planes was measured. The distances between the coronal suture and the anterior and posterior limits of the precentral gyrus

ABBREVIATIONS ACA = anterior cerebral artery; $\mathrm{AVM}=$ arteriovenous malformation; $\mathrm{MCA}=$ middle cerebral artery.

SUBMITTED February 11, 2014. ACCEPTED November 11, 2014.

INCLUDE WHEN CITING Published online January 2, 2015; DOI: 10.3171/2014.11.JNS14315.

DISCLOSURE Financial support was provided by the University of Florida Foundation. The authors report no conflict of interest concerning the materials or methods used in this study or the findings specified in this paper. 
were established at $1 \mathrm{~cm}$ intervals from their upper to their lower ends. The arterial branches supplying the central lobe were followed from their origin to their termination. The sylvian fissure was opened widely to determine the arterial trunks, stem arteries, and cortical branches supplying the central lobe. The veins and drainage pathways of the central lobe were defined.

\section{Results \\ Topographical Anatomy}

The lateral surface of the central lobe includes the precentral and postcentral gyri divided by a central sulcus and limited anteriorly by the precentral and posteriorly by the postcentral sulcus (Fig. 1). It folds over the superior border of the hemisphere to include the paracentral lobule, limited by the paracentral sulcus anteriorly, the ascending ramus of the cingulate sulcus posteriorly, and the cingulate sulcus below (Fig. 1C and D). The ascending ramus was present in all examined hemispheres and is easily seen on the MRI's sagittal cuts. Therefore it is a useful landmark in determining the position of the paracentral lobule. The paracentral sulcus was found in 50\% of the examined hemispheres.

The central sulcus is one of the most constant sulci on the cerebral surface. It is not usually interrupted above its lower end where a gyral bridge between the pre- and postcentral gyri called the subcentral gyrus (Broca's inferior frontoparietal pli de passage) separates the central sulcus from the sylvian fissure (Fig. 1; Table 1). ${ }^{9}$ The upper end opened directly into the interhemispheric fissure in most hemispheres..$^{19,46}$ The central sulcus was located an average of $5.3 \mathrm{~cm}$ (range $4.7-5.9 \mathrm{~cm}$ ) behind the coronal suture at its upper end and $3.8 \mathrm{~cm}$ (range $2.8-4.4 \mathrm{~cm}$ ) at its lower end.

From its upper end, the central sulcus has a posteriorto-anterior and medial-to-lateral trajectory forming an angle of approximately $20^{\circ}$ with the coronal plane passing through its upper end. It has 2 sinusoidal curves, or genua. Its upper half is gently convex posteriorly and its lower half is gently convex anteriorly (Figs. 1 and 2). ${ }^{40}$

The precentral gyrus has the same orientation and trajectory as the central sulcus and presents the same curvatures. The upper genu corresponds to the motor area of the hand (Fig. 1E). ${ }^{9,58}$ The anterior edge of the precentral gyrus was located an average of $3.6 \mathrm{~cm}$ (range 3.0-4.3 $\mathrm{cm}$ ) behind the coronal suture at its upper end and $2.3 \mathrm{~cm}$ (range 1.3-3.2 cm) at its lower end, but at the closest point, at approximately the level where the superior temporal line crosses the coronal suture, they were separated by an average of $1.8 \mathrm{~cm}$ (range $0.6-3.3 \mathrm{~cm}$; Table 2).

The lower third of the central sulcus has a relatively constant relationship with the central sulcus of the insula in that it coursed superficial and almost parallel to the central sulcus of the insula in 7 of 20 examined hemispheres (Fig. 1F). Of the remaining hemispheres, the lower end of the central sulcus was located an average of $0.2 \mathrm{~mm}$ anterior to the central insular sulcus in 7 cases and $0.41 \mathrm{~mm}$ posterior in 6 cases.

The precentral gyrus is positioned lateral to the following structures: the body of the lateral ventricle, the thalamus, the posterior limb of the internal capsule, the posterior part of the lentiform nucleus, and the midportion of the insula ${ }^{40}$ The precentral sulcus is positioned posterior to the pars opercularis of the inferior frontal gyrus, which provides a good anatomical reference for identifying the lower part of the precentral sulcus. At its upper end the precentral sulcus opened directly into the interhemispheric fissure in 9 of the 20 hemispheres and at its lower end directly into the sylvian fissure in 13 . The precentral sulcus was interrupted by 1-3 gyral bridges in all hemispheres (Table 1). These gyral bridges could connect the precentral gyrus to the superior, middle, or inferior frontal gyrus. The postcentral gyrus corresponds to the somatosensory area of the cerebrum. It is narrower than the precentral gyrus, a characteristic useful to differentiate the gyri in the surgical field. It also follows the curvatures of the central sulcus, and is typically segmented by gyral bridges. The postcentral sulcus opens directly into the interhemispheric fissure and/or the sylvian fissure in about half of the hemispheres (Table 1). The postcentral gyrus has a constant relationship with the intraparietal sulcus, typically coursing perpendicular to it. The intraparietal sulcus joined the postcentral sulcus in most hemispheres and is a useful anatomical landmark for surgical guidance and also a corridor to approach some atrial lesions ${ }^{42}$ It divides the parietal lobe into the superior and inferior parietal lobules. The postcentral gyrus is usually crossed by 1 or 2 gyral bridges connecting it to the superior parietal lobule and/or the supramarginal gyrus (Table 1). The inferior edge of the postcentral gyrus consistently faces the anterior transverse temporal (Heschl's) gyrus across the sylvian fissure..$^{57}$

\section{Craniometric Relationships of the Coronal Suture}

The coronal suture extends from the bregma (union between the sagittal and coronal sutures) above to its lower end at the pterion (area of convergence of frontal, temporal, sphenoid, and parietal bones; Fig. 2A, B, and D). It is easily palpable through the scalp and, therefore, is a helpful and reliable anatomical landmark. From its upper end, it has a descending trajectory from medial to lateral and posterior to anterior. Its upper portion runs almost perpendicular to the midline but near where it crosses the superior temporal line its forward inclination increases. It crosses the superior and inferior frontal sulci and has a trajectory somewhat parallel to the central lobe. It is longer than the precentral gyrus and the central sulcus. It had an average length of $10.5 \mathrm{~cm}$ (range 10.0-11.2 cm), while the length of the precentral gyrus and central sulcus averaged $10.1 \mathrm{~cm}$ (range 9.6-10.6 cm) and 9.5 cm (range 8.6-10.0 $\mathrm{cm}$ ), respectively.

As the coronal suture and the precentral gyrus descend from their upper ends, they converge, becoming closer together. A useful landmark, the point where the superior temporal line crosses the coronal suture, was located an average of $7.6 \mathrm{~cm}$ (range $7.1-8.6 \mathrm{~cm}$ ) lateral to the midline along the coronal suture and was usually at or near the level of maximal proximity (Fig. 2A and B). The closest point between the suture and the precentral gyrus was located approximately $6 \mathrm{~cm}$ lateral to the bregma along the coronal suture in $50 \%$ of the specimens and 7 or $8 \mathrm{~cm}$ 

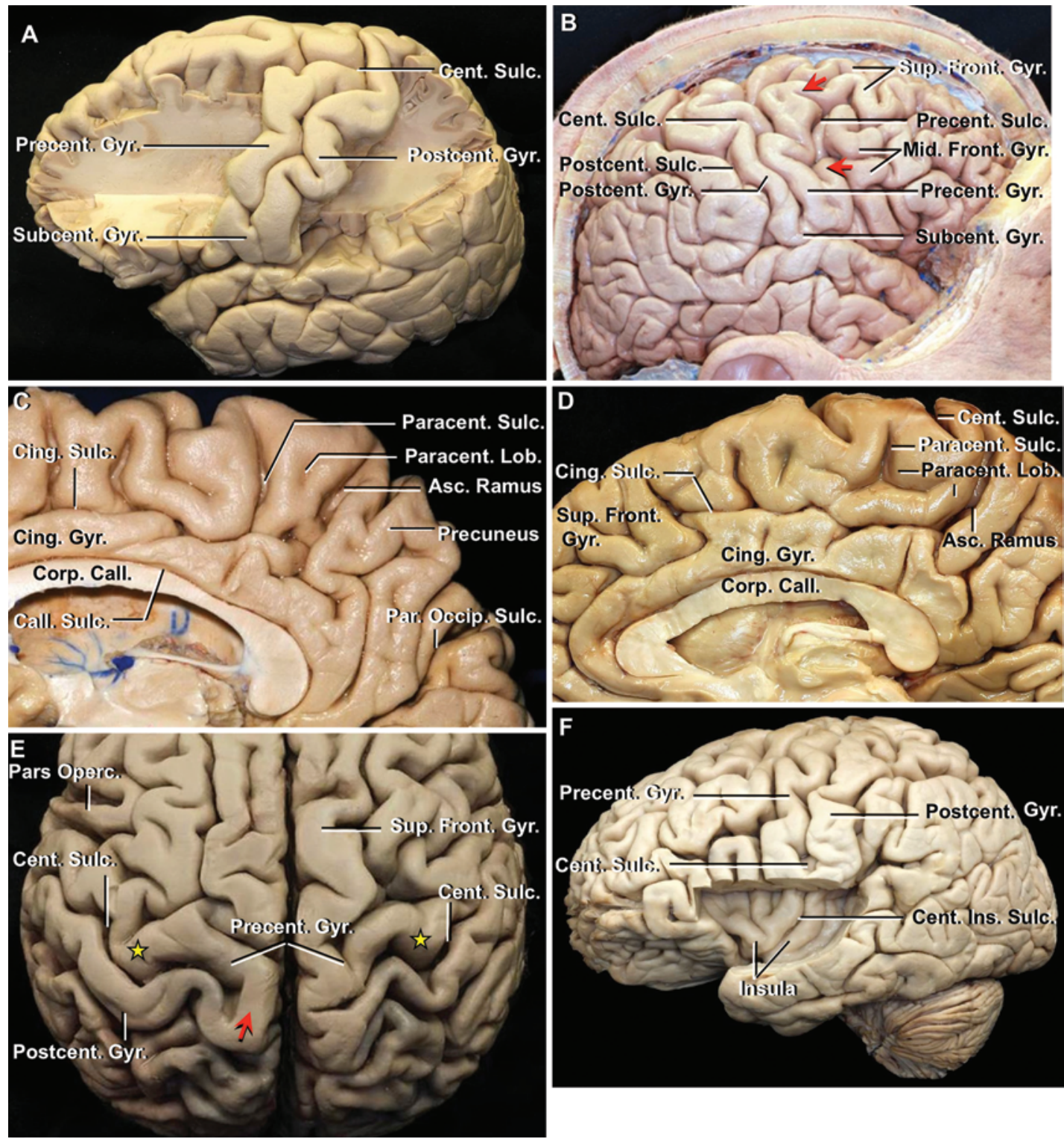

FIG. 1. Gyral and sulcal variations in multiple hemispheres. A: Part of the frontal and parietal lobes has been removed while preserving the pre- and postcentral gyri separated by a central sulcus. The central sulcus commonly opens directly into the interhemispheric fissure but is separated from the sylvian fissure by a gyral bridge, the subcentral gyrus. It has a gently convex posterior upper curve and a gently convex anterior lower curve. The shallow indention on the subcentral gyrus is not a sulcus but is related to an artery crossing the gyrus. B: Gyral bridges frequently interrupt the precentral and postcentral gyri but not the central sulcus (Table 1). The postcentral sulcus in this hemisphere is continuous and not interrupted by any gyral or sulcal bridge. The central sulcus opens into the interhemispheric fissure but is separated from the sylvian fissure by a subcentral gyrus. Two complex gyral bridges (red arrows) connect the superior and middle frontal gyri to the lower part of the precentral gyrus. $\mathrm{C}$ and D: Medial surface of two right hemispheres. C: The paracentral lobule is formed by the extension of the pre- and postcentral gyri onto the medial surface of the hemisphere. The paracentral lobule is limited posteriorly by the ascending ramus of the cingulate sulcus and anteriorly by the paracentral ramus of the cingulate sulcus. The paracentral sulcus was present in approximately half of hemispheres. The ascending ramus was found in nearly all hemispheres and is easily seen on MRI at the posterior edge of the paracentral lobule. The precuneus is located between the ascending ramus and the parietooccipital sulcus. D: The paracentral sulcus, which was absent in approximately $50 \%$ of hemispheres, does not reach the upper margin of this hemisphere. The anterior limit of the paracentral lobule can be determined by the overlap of the central sulcus onto the medial surface. E: Superior view. On the left hemisphere there is a large gyral bridge (red arrow) connecting the upper edges of the pre- and postcentral gyri and separating the upper end of the central sulcus from the interhemispheric fissure. The "hand knob" on the precentral gyrus is seen in both hemispheres (yellow stars). F: Lateral surface. The lower third of the central sulcus usually courses lateral and parallel to the central insular sulcus. Asc. = ascending; Cent. = central; Cing. = cingulate; Corp. Call. = corpus callosum; Front. = frontal; Gyr. = gyrus; Ins. = insular; Lob. = lobule; Mid. = middle; Occip. = occipital; Operc. = opercularis; Par. = parietal; Paracent. = paracentral; Postcent. = postcentral; Precent. = precentral; Subcent. = subcentral; Sulc. = sulcus; Sup. = superior. 
TABLE 1. Sulcal continuity and interruption by gyral bridges

\begin{tabular}{|c|c|c|c|}
\hline \multirow[b]{2}{*}{ Sulci } & \multicolumn{2}{|c|}{ No. of Hemispheres (\%) } & \multirow[b]{2}{*}{ Observation } \\
\hline & Continuity & Discontinuity & \\
\hline Central sulcus & $19(95)$ & $1(5)$ & Opened directly into the interhemispheric fissure in $80 \%$; subcentral gyrus found in $85 \%$ \\
\hline $\begin{array}{l}\text { Precentral } \\
\text { sulcus }\end{array}$ & $0(0)$ & $\begin{array}{l}1 \text { bridge in } 9 \text { (45), } 2 \text { bridges in } \\
7(35), 3 \text { bridges in } 4(20)\end{array}$ & $\begin{array}{l}\text { Opened directly into the interhemispheric fissure in } 45 \% \text { \& into the sylvian fissure in } \\
65 \%\end{array}$ \\
\hline $\begin{array}{l}\text { Postcentral } \\
\text { sulcus }\end{array}$ & $1(5)$ & $\begin{array}{l}1 \text { bridge in } 10(50), 2 \text { bridges } \\
\text { in } 9(45)\end{array}$ & $\begin{array}{l}\text { Opened directly into the interhemispheric fissure in } 45 \% \text { \& into the sylvian fissure in } \\
60 \% \text {; gyral bridges w/ superior parietal lobule in } 70 \% \text { \& supramarginal gyrus in } 65 \%\end{array}$ \\
\hline
\end{tabular}

in each of the other $25 \%$, respectively. After reaching the point of maximal convergence, the suture and the gyrus diverge toward their lower ends, where they are still closer than at their upper ends (Table 2). The anterior inclination of the central sulcus is greater in its upper half than in its lower half. The opposite happens with the coronal suture. Its inclination is lower in its upper half and greater at its lower end (Fig. 2E and F; Table 3).

\section{Arterial Supply}

The middle cerebral artery (MCA) and the anterior cerebral artery (ACA) supply the central lobe (Figs. 3 and 4). ${ }^{44}$ The pericallosal artery is the portion of the ACA distal to the anterior communicating artery that runs adjacent to the corpus callosum. It provides most of the cortical branches that supply the medial surface and the upper part of the lateral surface of the cerebrum, including the paracentral lobule and the upper portion of the central lobe, bordering the interhemispheric fissure. The callosomarginal artery is the largest branch of the ACA and is defined as the branch running in or above the cingulate sulcus that gives rise to 2 or more cortical branches. Its branches may also supply the paracentral lobule as well as the upper portion of the central lobe on the lateral surface.

The ACA cortical branches that contribute to the arterial supply of the central lobe were the posterior internal frontal, paracentral, and superior parietal arteries (Fig. 3). The posterior internal frontal artery coursed along and supplied some of the medial surface of the frontal lobe. It had an upward and backward trajectory folding around the superior margin to reach the lateral surface, and supplied the anterosuperior part of the precentral gyrus in 18 hemispheres. It did not provide any supply to either the paracentral lobule or the postcentral gyrus. The posterior internal frontal artery arose from the callosomarginal artery in 7 hemispheres and the pericallosal artery in 13. In 8 hemispheres it supplied the full width of the precentral gyrus and in 10 the anterior half only. The lowest point reached on the lateral surface by the posterior internal frontal artery was $3 \mathrm{~cm}$ lateral to the superior edge of the precentral gyrus (Fig. 3).

The paracentral artery arose from the pericallosal artery in 15 hemispheres and the callosomarginal artery in 5, and it commonly coursed on the cingulate sulcus between the paracentral sulcus and the ascending ramus of the cingulate sulcus. Above the cingulate sulcus, before reaching the ascending ramus, it turned up toward the superior border and gave branches that supplied the paracentral lobule and the upper portion of the pre- and postcentral gyri on the lateral surface. It supplied the anterior part of the paracentral lobe in all hemispheres and the posterior portion in 17 of 20 hemispheres. After folding over the superior margin of the hemisphere, it supplied the upper portion of the precentral gyrus in 14 hemispheres and the upper portion of the postcentral gyrus in 16 hemispheres. On the lateral surface it reached as low as $1.6 \mathrm{~cm}$ from the superior border.

The superior parietal branch of the pericallosal artery arose anterior to the splenium of the corpus callosum and coursed in or close to the ascending ramus of the cingulate sulcus. It supplied the anterior portion of the paracentral lobule in 5 hemispheres and the posterior portion in 17 hemispheres. On the lateral surface, it irrigated the upper part of the postcentral gyrus in 8 hemispheres. It did not supply the precentral gyrus. The most common area supplied by the superior parietal artery in the central lobe was the posterior portion of the paracentral lobule.

The MCA supplies the entire central lobe on the lateral surface, except the upper part bordering the superior margin of the hemisphere supplied by the cortical branches of the ACA (Figs. 4 and 5). ${ }^{44}$ The MCA bifurcated into superior and inferior trunks in 16 hemispheres and trifurcated into anterior, middle, and superior trunks in 4 hemispheres. The central lobe was supplied by the central, precentral, and anterior parietal branches of the MCA.

The central artery supplied a larger part of the central lobe than any other artery (Figs. 4-6). It arose from a stem artery (the arterial segment between a postbifurcation trunk and a cortical branch) as double or triple branches. In this study the central artery was found to be a double artery in $80 \%$ of the specimens and a triple artery in $20 \%$. It supplied part of the precentral and postcentral gyri in all hemispheres. The most frequent pattern found (14 hemispheres) was for the central artery to arise from a stem artery arising from the superior trunk at or slightly before the stem artery exited the sylvian fissure (Figs. 5 and 6). In the MCAs with a trifurcation, the stem artery that gave origin to the central arteries arose from the middle trunk. In 2 hemispheres a small central artery arose from the inferior trunk.

The precentral artery irrigated the anterior portion of the precentral gyrus in 14 hemispheres. It arose from a superior trunk in 18 hemispheres, from a middle trunk of an MCA trifurcation in 1, and from an early frontal branch in 1. It did not reach the postcentral gyrus in any hemisphere.

The anterior parietal artery irrigated the posterosuperior portion of the postcentral gyrus in 16 hemispheres. It arose from the superior trunk in 14 hemispheres and from the inferior trunk in 2 hemispheres. In 6 hemispheres it 

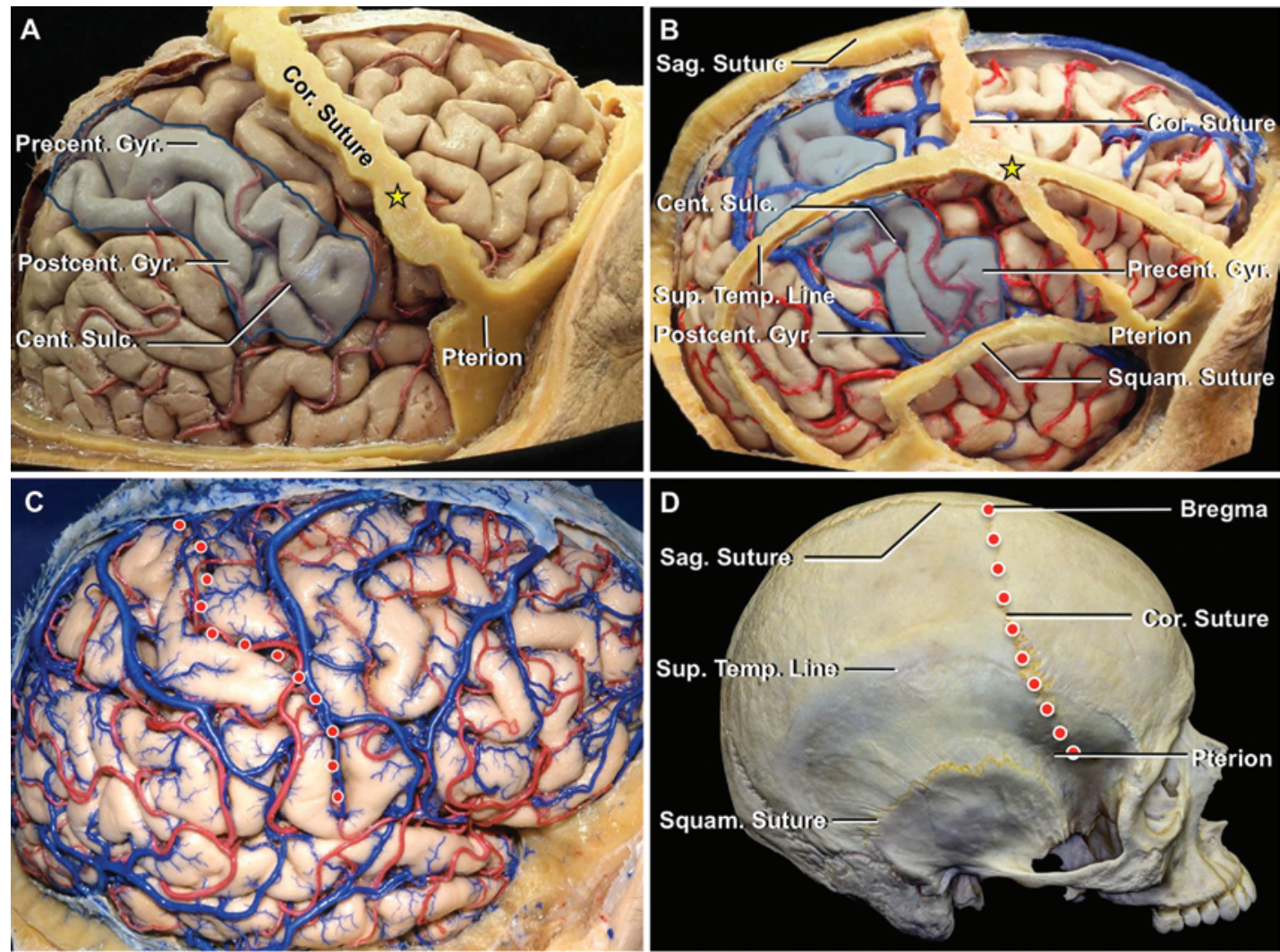

E

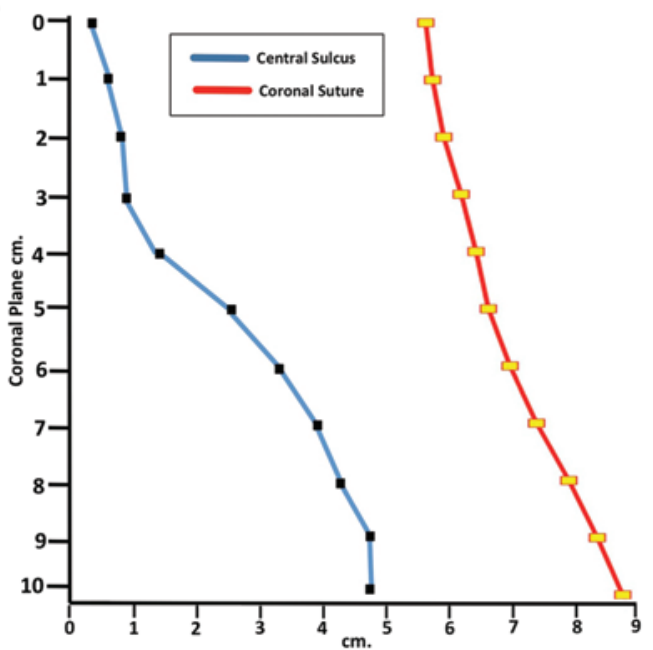

$\mathrm{F}$

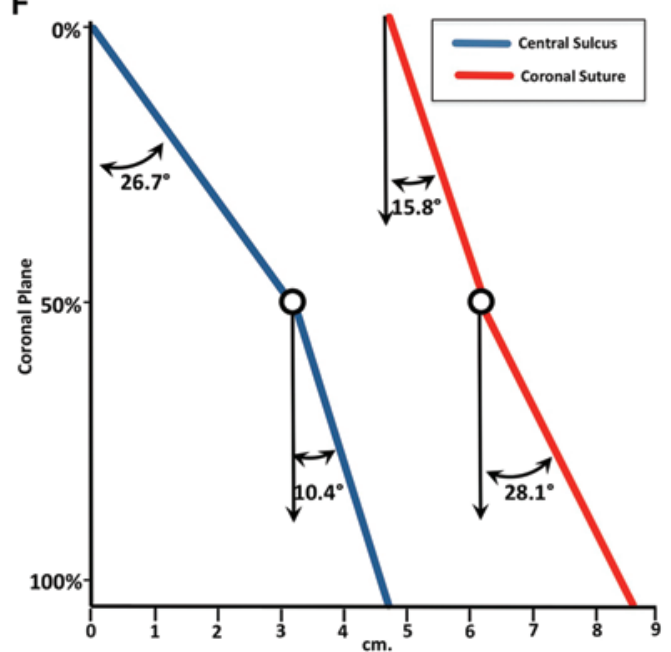

FIG. 2. A: The right coronal suture and the precentral gyrus converge as they descend from their upper ends and become closer. The point of maximal convergence is approximately at the junction of the superior temporal line and the coronal suture (yellow star). This point, named the stephanion, is located an average of $7.6 \mathrm{~cm}$ lateral to the midline along the coronal suture. B: The anterior edge of the right precentral sulcus is closest to the coronal suture around $1 \mathrm{~cm}$ lateral to the point where the superior temporal line crosses the coronal suture (yellow star) as was found in $25 \%$ of the hemispheres. Below this point they diverge, but their lower ends remain closer than their upper ends. C and D: Typical course of the central sulcus (C) and coronal suture (D) (red dots measured at 1-cm intervals) starting superiorly at the interhemispheric fissure. E: Graph showing the distance between the coronal suture and central sulcus starting above at the interhemispheric fissure and at every $\mathrm{cm}$ along their descent in 20 hemispheres (Table 2). As they run downward and lateral from the vertex, they converge to near where they cross the superior temporal line after which they diverge. The lower end of the central sulcus is closer to the coronal suture than the upper end. F: Graph showing the average inclination of the upper and lower halves of the coronal suture and central sulcus in comparison with the coronal plane passing through the upper end of their upper and lower halves in 20 hemispheres (Table 3). The central sulcus is steeper in the lower than the upper half. The opposite is true for the coronal suture, for which the upper half is steeper than the lower half. Cor. = coronal; Sag. = sagittal; Squam. = squamous; Sup. = superior; Temp. = temporal. 
TABLE 2. Distance between the coronal suture and the anterior and posterior limits of the precentral gyrus starting at their upper ends and at every centimeter to their lower ends in 20 hemispheres*

\begin{tabular}{lccccc}
\hline \multirow{2}{*}{ Point } & \multicolumn{2}{c}{ Anterior Limit } & & \multicolumn{2}{c}{ Posterior Limit } \\
\cline { 2 - 3 } \cline { 5 - 6 } & Mean (range) $\dagger$ & SD $\dagger$ & & Mean (range) $\dagger$ & SD $\dagger$ \\
\hline Upper end & $3.6(3.0-4.3)$ & 0.4 & & $5.3(4.7-5.9)$ & 0.4 \\
\hline $1 \mathrm{~cm}$ & $3.5(2.4-4.4)$ & 0.5 & & $5.2(4.5-6.0)$ & 0.4 \\
\hline $2 \mathrm{~cm}$ & $3.5(2.4-5.1)$ & 0.6 & & $5.1(4.1-6.3)$ & 0.6 \\
\hline $3 \mathrm{~cm}$ & $3.1(2.3-4.2)$ & 0.5 & & $5.1(4.2-5.7)$ & 0.5 \\
\hline $4 \mathrm{~cm}$ & $2.6(1.6-3.7)$ & 0.6 & & $4.8(3.8-5.6)$ & 0.5 \\
\hline $5 \mathrm{~cm}$ & $2.3(1.4-3.5)$ & 0.6 & & $3.8(2.8-4.7)$ & 0.6 \\
\hline $6 \mathrm{~cm}$ & $1.8(1.1-3.3)$ & 0.6 & $3.6(2.7-4.5)$ & 0.5 \\
\hline $7 \mathrm{~cm}$ & $1.8(0.6-3.3)$ & 0.7 & $3.4(2.3-4.3)$ & 0.6 \\
\hline $8 \mathrm{~cm}$ & $1.9(0.5-3.2)$ & 0.8 & $3.4(2.4-4.4)$ & 0.5 \\
\hline $9 \mathrm{~cm}$ & $2.1(1.2-3.2)$ & 0.6 & $3.5(2.4-4.3)$ & 0.4 \\
\hline Lower end & $2.3(1.3-3.2)$ & 0.6 & $3.8(2.8-4.2)$ & \\
\hline
\end{tabular}

* See Fig. $2 \mathrm{E}$.

$\dagger$ Values are presented in centimeters.

arose from a stem artery with the posterior parietal artery and in 1 with the central artery.

\section{Most Frequent Arterial Pattern}

\section{Medial Surface, Paracentral Lobule}

The paracentral lobule is supplied predominantly by the paracentral artery with the superior parietal artery supplying the inferior and posterior margins.

\section{Lateral Surface, Superior Third}

The upper part of the lateral surface is supplied by the paracentral, posterior interior frontal, and superior parietal arteries, which arise on the medial surface. The lower part of the upper third is supplied by the central and anterior parietal arteries, which ascend from below (Figs. 3 and 5).

\section{Lateral Surface, Middle and Inferior Thirds}

These portions of the paracentral lobule are supplied predominantly by the central artery, except for small areas along the anterior and posterior margin, which are supplied by the precentral and anterior parietal arteries, respectively.

\section{Venous Drainage}

This study revealed considerable variability of drainage (Figs. 7 and 8). The drainage of the central lobe is usually directed to 1 or more of 3 sinuses - superior sagittal, transverse, and sphenoparietal-although in rare cases it may drain to the cavernous or inferior sagittal sinus. ${ }^{39}$ The paracentral lobule and the upper two-thirds of the lateral surface frequently drain to the superior sagittal sinus. The lower third of the lateral surface most commonly drains to the superficial sylvian veins and from there to the transverse sinus via the vein of Labbé or anteriorly to the sphenoparietal sinus.

The anastomotic veins on the lateral surface that interconnect the drainage groups are the superficial sylvian vein and the veins of Labbe and Trolard (Fig. 7). The vein of Trolard, called the superior anastomotic vein, is the largest anastomotic vein. It crossed the lateral surface of the parietal and frontal lobes, connecting the superior sagittal sinus to the veins of the sylvian fissure. It frequently crossed the lateral surface as a central, precentral, or postcentral vein and could be duplicated as well. It was usually joined by other veins before emptying into the superior sagittal sinus. The vein of Labbé, also called the inferior anastomotic vein, crossed the temporal lobe connecting the superficial sylvian veins with the transverse sinus. It commonly began at the mid part of the sylvian fissure and ran posteriorly and inferiorly toward the anterior part of the transverse sinus (Fig. 7A and F). It can be a middle, anterior, or posterior temporal vein and can be a duplicate vein as well. The superficial sylvian vein ran along the sylvian fissure and drained anteriorly into the sinuses along the sphenoid ridge or posteriorly into the vein of Labbé, or both. It received several tributaries along its course (frontoparietal and temporosylvian veins) and usually emptied into the sphenoparietal sinus or, in 1 hemisphere, directly into the cavernous sinus. In rare cases it may continue posteriorly to drain into the superior petrosal sinus. ${ }^{39}$

\section{Cortical Veins}

The central lobe was drained by veins on both the me-

TABLE 3. Table showing the average angle of the upper and lower half of the coronal suture and central sulcus in comparison to the coronal plane passing through the upper end of their upper and lower halves in 20 hemispheres*

\begin{tabular}{lll}
\hline \multicolumn{1}{c}{ Microsurgical Structure } & Mean (range) $\dagger$ & SD $\dagger$ \\
\hline Coronal suture & & \\
\hline Upper end to midpoint of length & $15.8(12.1-21.1)$ & 3.0 \\
\hline$\quad$ Midpoint of length to lower end & $28.1(24.0-34.2)$ & 3.3 \\
\hline Central sulcus & & \\
\hline$\quad$ Upper end to midpoint of length & $26.7(19.3-32.5)$ & 4.3 \\
\hline$\quad$ Midpoint of length to lower end & $10.4(1.5-15.9)$ & 3.6 \\
\hline * See Fig. 2F. & & \\
$\dagger$ &
\end{tabular}



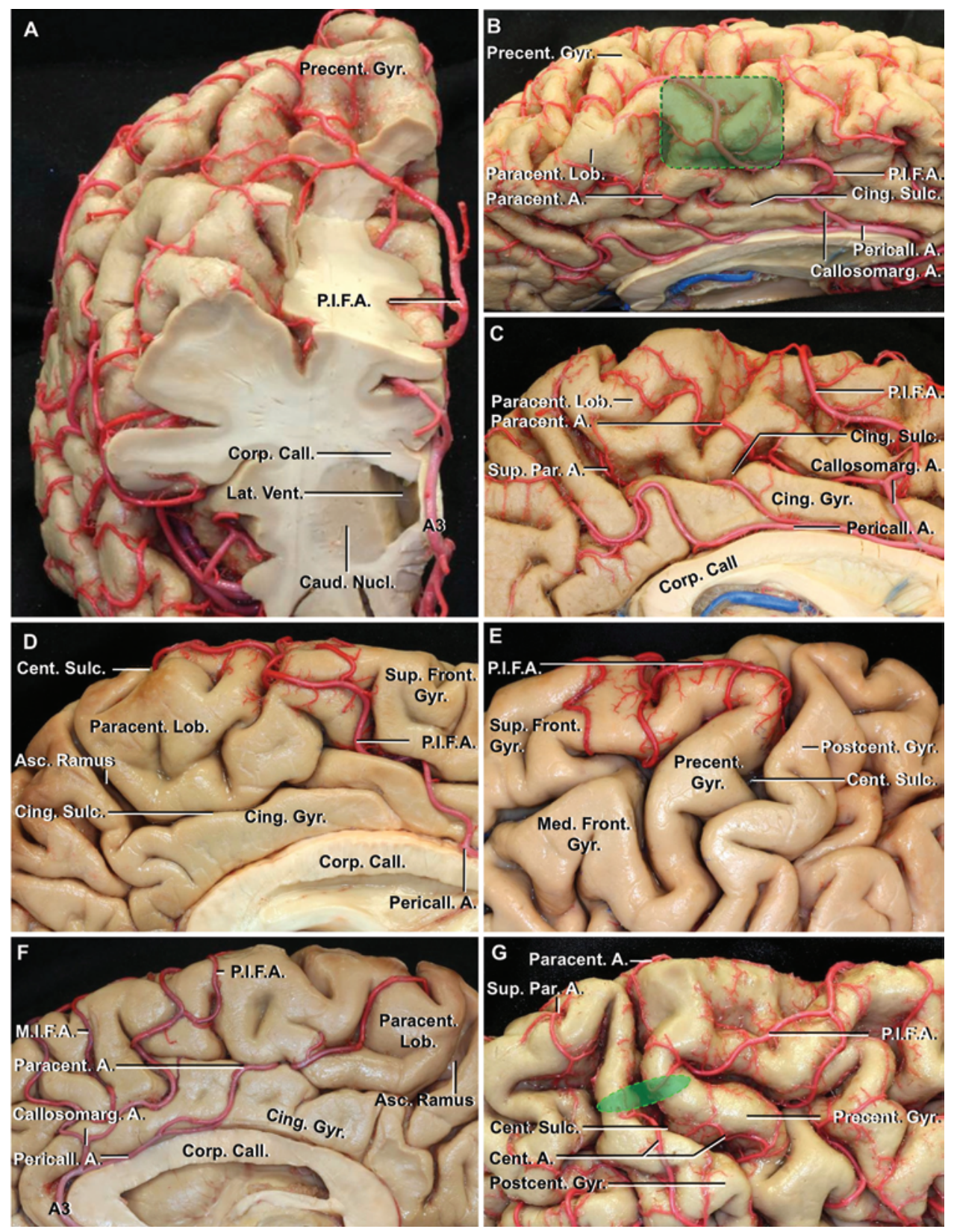

FIG. 3. A: The anterior part of the frontal lobe was removed using a coronal cut anterior to the foramen of Monro. The upper part of the superior frontal gyrus was removed to expose the course of the posterior internal frontal artery, which folds over the superior margin of the lateral surface approximately $1.5 \mathrm{~cm}$ anterior to the precentral gyrus after supplying the supplementary motor area. It also supplies the superior portion of the precentral gyrus on the lateral surface but not the paracentral lobule on the medial surface. B: The callosomarginal artery gives rise to the posterior internal frontal and paracentral arteries. The posterior internal frontal artery folds over the superior margin of the lateral surface and supplies the supplementary motor area (green shaded area) and the superior portion of the precentral gyrus. The paracentral artery courses inside the cingulate sulcus before turning upward to supply the paracentral lobule and a small portion of the upper part of the postcentral gyrus. Sacrificing these arteries may lead to a supplementary motor area syndrome with contralateral lower-limb weakness. C: An enlarged view of the paracentral lobule. The paracentral lobule is commonly supplied by the paracentral and superior parietal arteries. In this hemisphere the superior parietal artery is a branch of the pericallosal artery and runs in the ascending ramus of the cingulate sulcus to supply the lower and posterior borders of the paracentral lobule. The paracentral artery, a branch of the callosomarginal artery, courses in the cingulate sulcus and supplies the majority of the paracentral lobule. D-G: Other arteries have been removed to show the trajectory and area of supply of the left posterior internal frontal artery. D: Medial surface of left hemisphere. This posterior internal frontal artery arises from the pericallosal artery, runs upward and posterior to supply the posterior portion of the medial surface of the superior frontal gyrus. It folds over the superior margin of the hemisphere anterior to the paracentral lobule. E: Upper lateral surface of the left hemisphere shown in D. The posterior internal frontal artery folds around the superior border anterior to the central lobe to supply the posterior portion of the superior frontal gyrus and the upper part of the precentral gyrus. F: Medial surface of a right hemisphere. The callosomarginal artery arises from the precallosal segment of the pericallosal artery and gives rise to both the middle and posterior internal frontal arteries. The paracentral artery arises from the pericallosal artery and courses upward to reach the anterior part of the paracentral lobule. G: Superior part of the lateral surface of the right hemisphere shown in F. FIG. 3 (continued) $\rightarrow$ 
FIG. 3. G (continued): The watershed area between the ACA and MCA is located approximately $1.5 \mathrm{~cm}$ lateral to the superior margin of the lateral surface (green shaded area), where there are anastomoses between branches of the MCA and ACA. The posterior internal frontal artery runs in an anterior to posterior direction. The watershed area is supplied by the central branches of the MCA and by the posterior internal frontal, paracentral, and superior parietal branches of the ACA. A. = artery; Callosomarg. = callosomarginal; Caud. = caudate; Lat. = lateral; Med. = medial; M.I.F.A. = middle internal frontal artery; Nucl. = nucleus; P.I.F.A. = posterior internal frontal artery; Pericall. = pericallosal; Vent. = ventricle.
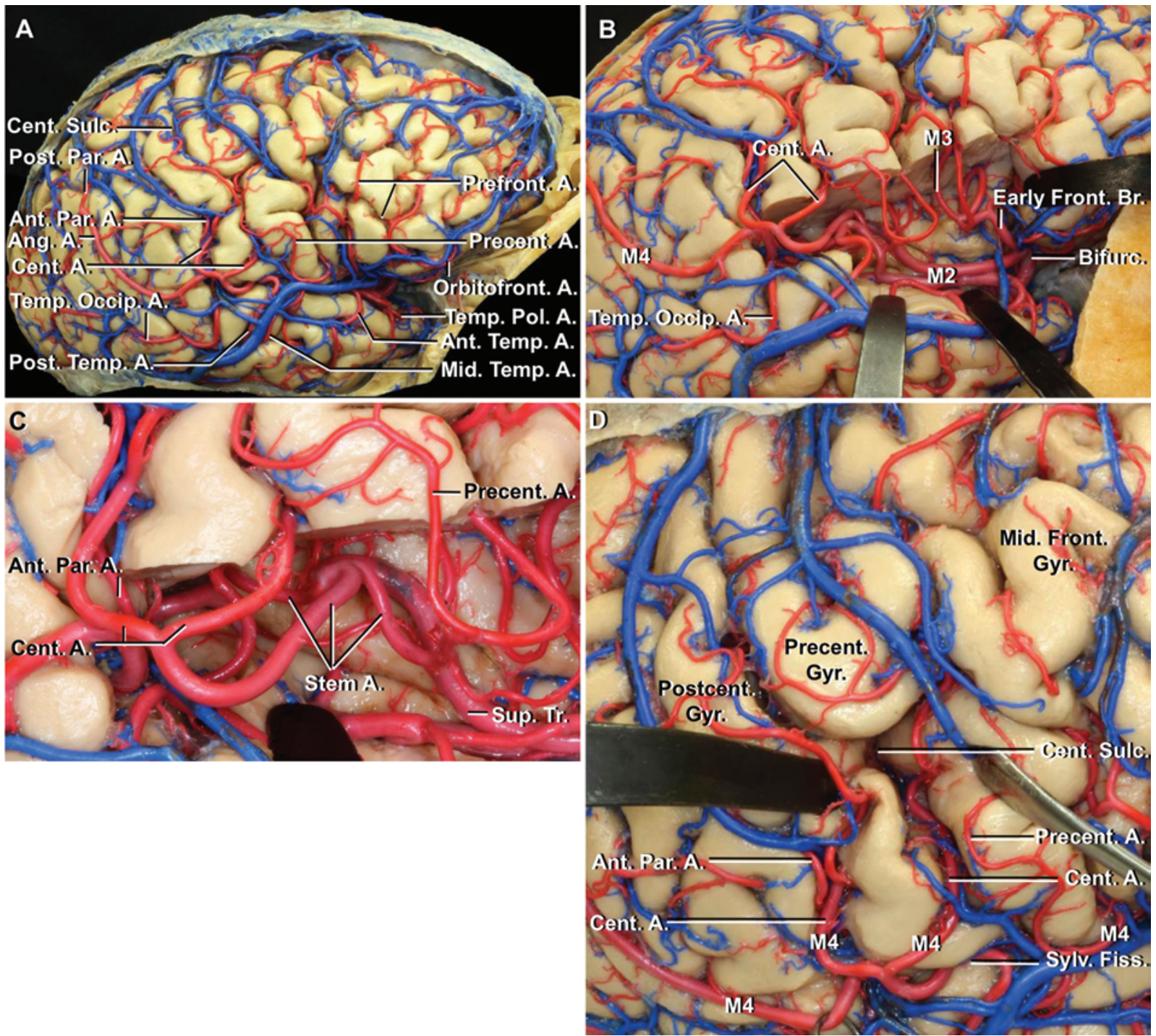

FIG. 4. A: Right cerebral hemisphere. The cortical distribution of the MCA includes most of the lateral surface of the hemisphere and all the insular and opercular surfaces. The cortical branches anastomose with the terminal branches of the ACA approximately $1.5 \mathrm{~cm}$ lateral to the superior border. The $\mathrm{M}_{4}$, composed of the cortical branches of the MCA usually begins at the surface of the sylvian fissure and runs on the lateral surface commonly within the sulci. The cortical branches of the $\mathrm{M}_{4}$ segment, named based on their supply to 12 different areas, are as follows: orbitofrontal, prefrontal, central, anterior parietal, posterior parietal, angular, temporooccipital, posterior temporal, middle temporal, anterior temporal, and temporopolar. ${ }^{43}$ B: View of the $\mathrm{M}_{2}, \mathrm{M}_{3}$, and $\mathrm{M}_{4}$ segments. The bifurcation occurs just proximal to the genu. The $\mathrm{M}_{2}$ is constituted by the trunks that cross and supply the insula and end at the limiting sulci of the insula. The $\mathrm{M}_{3}$ segment starts at or near the limiting sulci where the $\mathrm{M}_{2}$ branches turn to course on the frontoparietal and temporal opercula. The $\mathrm{M}_{4}$ segment is formed by the cortical branches. In this hemisphere the inferior trunk gives rise to the temporopolar, anterior temporal, middle temporal, posterior temporal, temporooccipital, angular and posterior parietal branches. An early frontal branch gives origin to the orbitofrontal and prefrontal arteries. The superior trunk gives rises to the precentral, central, and anterior parietal branches. C: Enlarged view. The cortical arteries that supply the central lobe can be followed from their origin on the postbifurcation trunks on the insular surface to the cortex. The superior trunk gives rise to 3 stem arteries from which the cortical branches arise. The anterior stem artery bifurcates into the precentral arteries that supply the lower portion of the precentral gyrus, and the large stem artery bifurcates and gives rise to 2 central arteries in what was found to be a frequent pattern. Another stem artery arose from the superior trunk as a single branch to become the anterior parietal artery. D: The central artery arises at the outer edge of the sylvian fissure as a double artery and supplies most of the central lobe. The precentral artery supplies the lower part of the precentral gyrus. The anterior parietal artery supplies the middle third of the posterior portion of the postcentral gyrus. Ang. $=$ angular; Ant. = anterior; Ant. Par. $=$ anterior parietal; Bifurc. = bifurcation; br. = branch; Fiss. = fissure; Orbitofront. = orbitofrontal; Post. = posterior; Prefront. = prefrontal; Sylv. = sylvian; Temp. Pol. $=$ temporopolar; Temp. Occip. = temporooccipital; Tr. = trunk. 

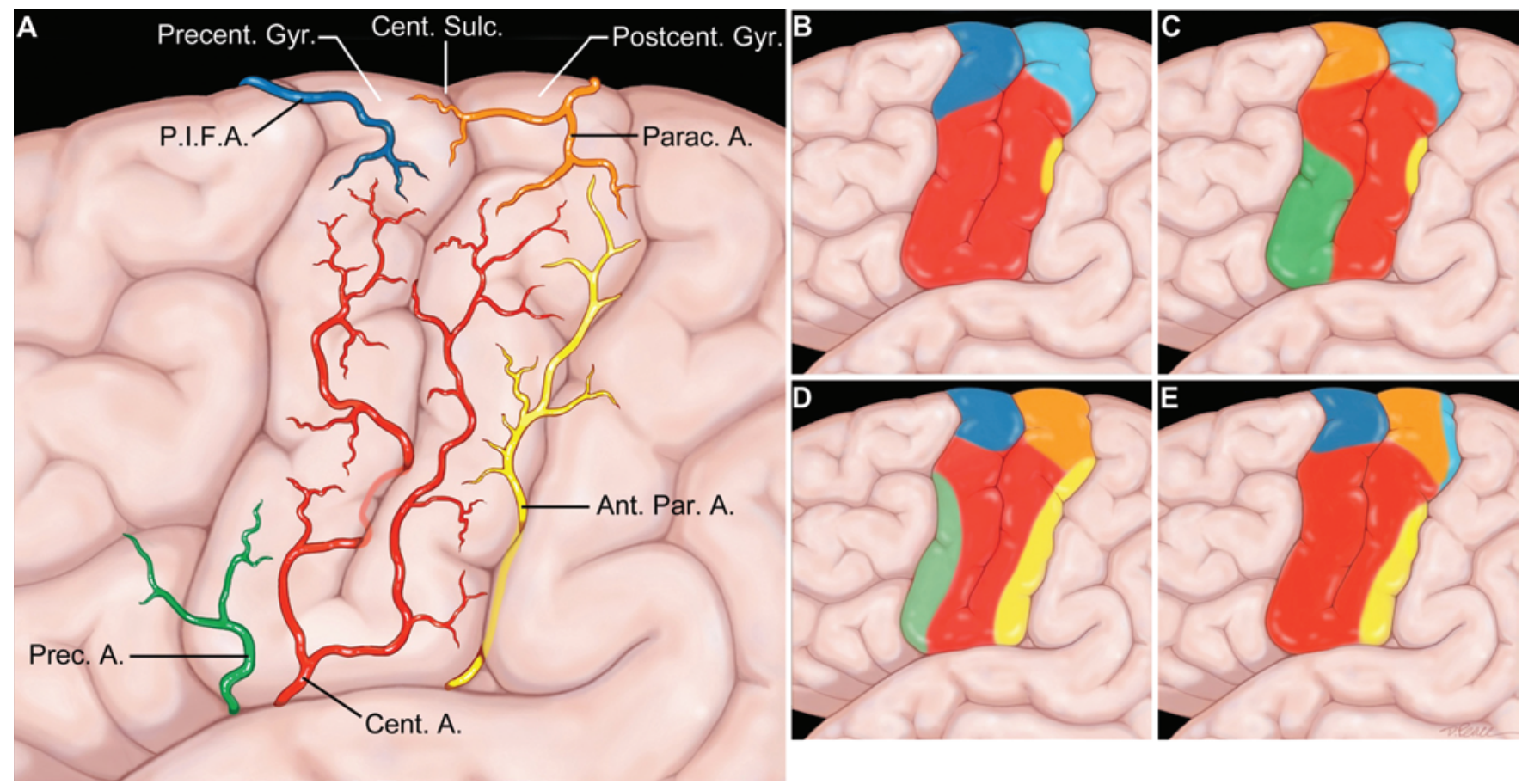

FIG. 5. A-E: Arterial supply of the lateral surface of the central lobe: posterior internal frontal artery (dark blue), paracentral artery (orange), superior parietal artery (light blue), precentral artery (green), central artery (red), and anterior parietal artery (yellow). A: Most common pattern. The posterior interior frontal and paracentral branches of the ACA supply the upper part. The majority of the lateral surface is supplied by the central branch of the MCA. The areas not supplied by the central artery are the anterior inferior part of the precentral gyrus supplied by the precentral and the posterior edge of the postcentral gyrus supplied by the anterior parietal artery. These cortical arteries often course in the sulci as well as on the surface of the gyri. B-E: Frequently encountered variations. B: The lower two-thirds of the central lobe is predominantly supplied by the central artery. On the superior third, the precentral gyrus is supplied by the posterior interior frontal artery and the postcentral gyrus by the superior parietal artery. C: The superior parts of the precentral and postcentral gyri are supplied by the paracentral and superior parietal arteries, respectively. There is no supply from the posterior inferior frontal artery. A larger than usual area of the precentral gyrus is supplied by the precentral artery. D: The precentral and the anterior parietal arteries have a larger than usual area of supply that narrows the large proximal area usually supplied by the central artery. The superior third is supplied by the posterior internal frontal and paracentral arteries. E: There is no contribution from the precentral artery. The anterior parietal artery supplies the lower two-thirds of the posterior part of the postcentral gyrus. The area supplied by the cortical branches of the ACA is divided between the posterior interior frontal, paracentral, and superior parietal arteries. Parac. $=$ paracentral; Prec./Precent. = precentral. Copyright Albert $\mathrm{L}$. Rhoton Jr. Published with permission.

dial and lateral surface of the hemisphere. The veins on the lateral surface could empty into ascending or descending groups (Figs. 7 and 8). ${ }^{39}$

\section{Lateral Surface, Ascending Group}

The central vein usually drained the largest portion of the central lobe, even reaching the lower portion in some cases. It drained all or part of the pre- and postcentral gyri in $90 \%$ of hemispheres. The precentral vein usually drained the anterior portion of the precentral gyrus. It drained the precentral gyrus in 14 hemispheres and the postcentral gyrus in 1 hemisphere. The postcentral vein is the one most commonly connecting both the sagittal sinus and superficial sylvian vein to form a vein of Trolard. It drained the posterior part of the postcentral gyrus and most commonly emptied into the superior sagittal sinus. The postcentral vein drained the postcentral gyrus in 15 hemispheres. It did not drain the precentral gyrus in any hemisphere.

The middle and posterior frontal veins infrequently drain the central lobe and in this study drained the precentral gyrus in only 1 hemisphere each. The anterior pa- rietal vein usually drains the angular and supramarginal gyri and in this study drained the postcentral gyrus in 2 hemispheres.

\section{Lateral Surface, Descending Group}

The frontosylvian veins drained the frontal operculum and emptied into the superficial sylvian veins. They drained the precentral gyrus in 18 hemispheres and the postcentral gyrus in 1 hemisphere. The parietosylvian veins drained the postcentral gyrus and emptied into the superficial sylvian veins in 15 hemispheres. In 4 hemispheres the postcentral gyrus was drained directly by the vein of Trolard.

\section{Medial Surface}

The medial posterior frontal vein drained the medial frontal lobe and the cingulate gyrus above the genu of the corpus callosum. It drained the anterior margin of the paracentral lobule in 1 hemisphere. The paracentral vein drained the anterior portion of the paracentral lobule in all hemispheres and the posterior portion in 15 . It emptied 


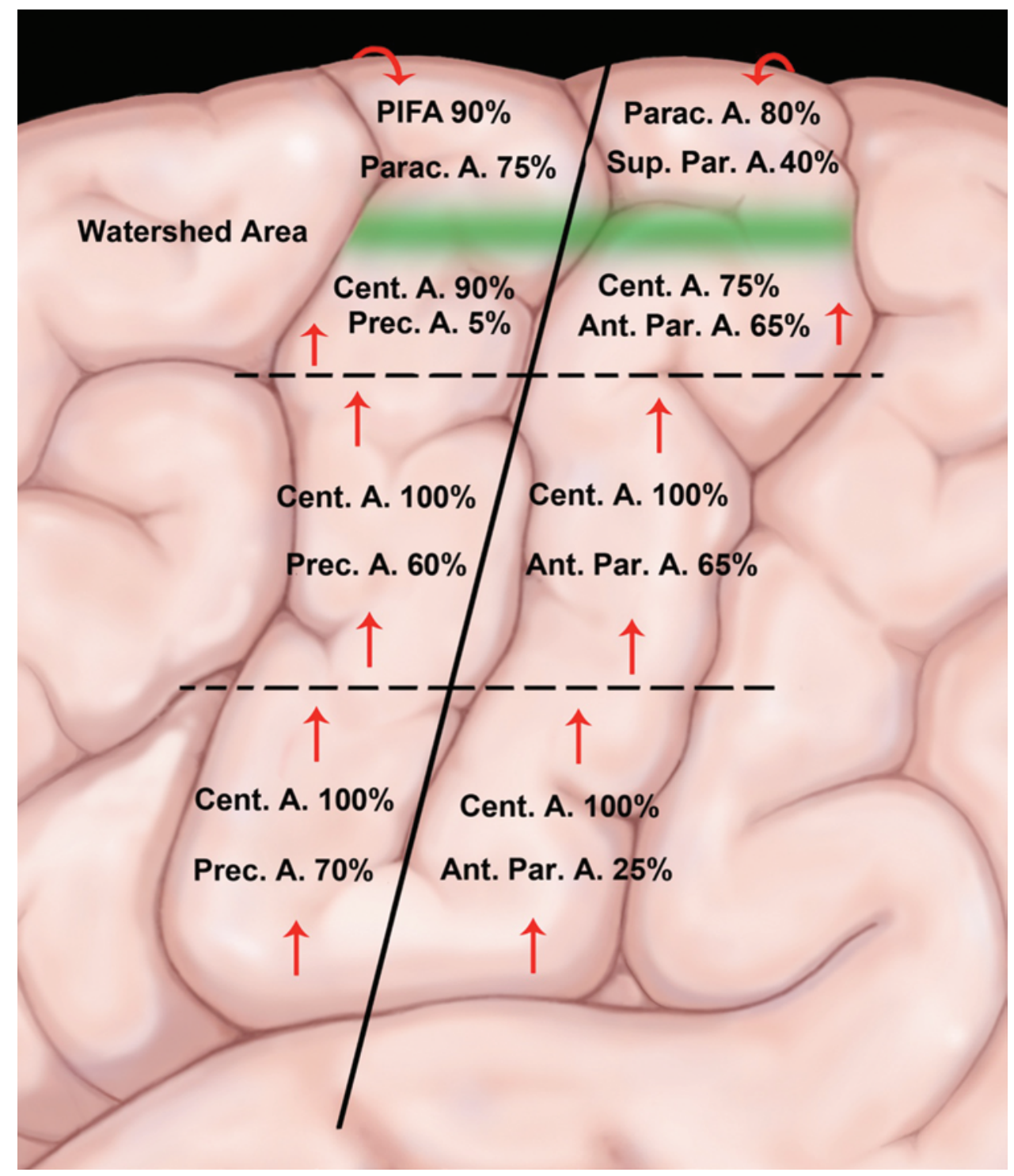

FIG. 6. Illustration showing the percentage of cortical branches of the ACA and MCA that supply the upper, middle, and lower thirds of the central lobe. The watershed area between the ACA and MCA is located approximately $1.5 \mathrm{~cm}$ lateral to the superior margin (green shaded area). The branches of the MCA (central, precentral, and anterior parietal arteries) arise near the surface of the sylvian fissure and ascend to anastomose with the descending cortical branches of the ACA (posterior interior frontal, paracentral, and superior parietal arteries), which fold around the superior margin. Copyright Albert L. Rhoton Jr. Published with permission.

into the superior sagittal sinus. In 4 hemispheres the drainage of the paracentral lobule was exclusively through the paracentral veins. The anteromedial parietal vein drained the posterior part of the paracentral lobule in 15 hemispheres and the anterior part in 3 hemispheres. It emptied into the superior sagittal sinus or into a large cortical vein on the lateral surface. It usually drains the precuneus.

\section{Sinus Drainage}

In 19 of 20 hemispheres, the superior two-thirds of the paracentral lobule drained to the superior sagittal sinus (Figs. 7 and 8). In 2 hemispheres the middle third of the postcentral gyrus drained to the transverse sinus. The inferior third of the precentral gyrus drained to the sphenoparietal sinus in 10 hemispheres, to the transverse sinus via the vein of Labbé in 8 , and to the superior sagittal sinus in 2. The lower portion of the postcentral gyrus drained to the sphenoparietal sinus in 7, the transverse sinus in 9, and to the superior sagittal sinus via the vein of Trolard in 4 hemispheres.

The vein of Trolard contributed to the venous drainage of the central lobe in 15 hemispheres. It was located at the site of the postcentral vein in 8, central vein in 3 , precentral vein in 2 , anterior parietal vein in 1 , and was duplicated in 1 hemisphere where it was located at the site of the precentral and central veins.

\section{Most Common Drainage Pattern}

Medial Surface

The majority of the paracentral lobule drained through 

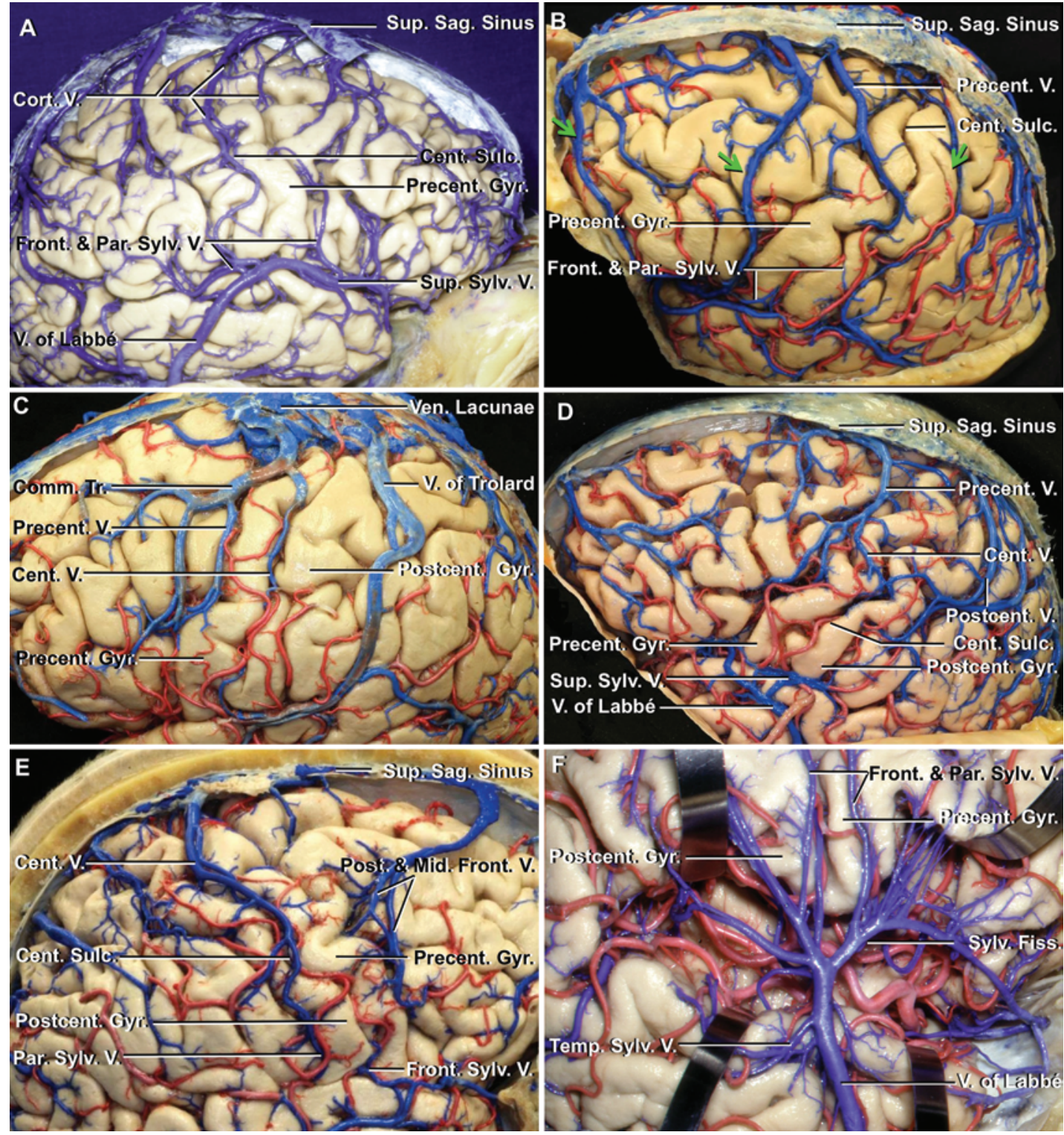

FIG. 7. A-F: Venous drainage of the central lobe. A: A common pattern of drainage. The superior two-thirds of the right hemisphere is drained by the cortical veins emptying into the superior sagittal sinus. The inferior third drains through the frontosylvian and parietosylvian veins to a superficial sylvian vein that empties into a large vein of Labbé and the transverse sinus. B: Three veins of Trolard (green arrows) crossed this left hemisphere, connecting the superficial sylvian vein with the superior sagittal sinus. The posterior part of the central lobe is drained through the posterior vein of Trolard. A precentral vein drains a large portion of the central lobe. The inferior third is drained by the frontosylvian and parietosylvian veins, except for the anterior part of the precentral gyrus, which drains through the middle anastomotic vein of Trolard. C: A large common trunk receives drainage from several cortical veins before passing below a large venous lacuna to empty into the superior sagittal sinus. The majority of the posterior right central lobe is drained by central and precentral veins that pass below this lacuna. The posterior part of the central lobe drains to the superior sagittal sinus through a large anastomotic vein of Trolard. D: A large precentral vein drained the majority of the superior two-thirds of the precentral gyrus. The central vein drained a portion of the precentral gyrus and emptied into the larger precentral vein that emptied into the superior sagittal sinus. The inferior third of the central lobe drained into a hypoplasic superficial sylvian vein joined to a vein of Labbé that emptied into the transverse sinus. The superior two-thirds of the postcentral gyrus is drained by a postcentral vein that empties into the superior sagittal sinus. $\mathrm{E}$ : The right central lobe is drained predominantly by a large central vein that empties into the superior sagittal sinus. A small portion of the anterior edge of the precentral gyrus is drained by the posterior and middle frontal veins that form a common trunk before emptying into the superior sagittal sinus. The lower portion of the central lobe is drained by frontosylvian and parietosylvian veins that empty into the superficial sylvian vein. $\mathrm{F}$ : Enlarged view of the opercular region of another right hemisphere. The lower portion of the central lobe is drained by frontosylvian and parietosylvian veins that empty into a superficial sylvian vein that emptied predominantly through a large vein of Labbé into the transverse sinus. Comm. = communicating; Cort. = cortical; V. = vein; Ven. = venous . 


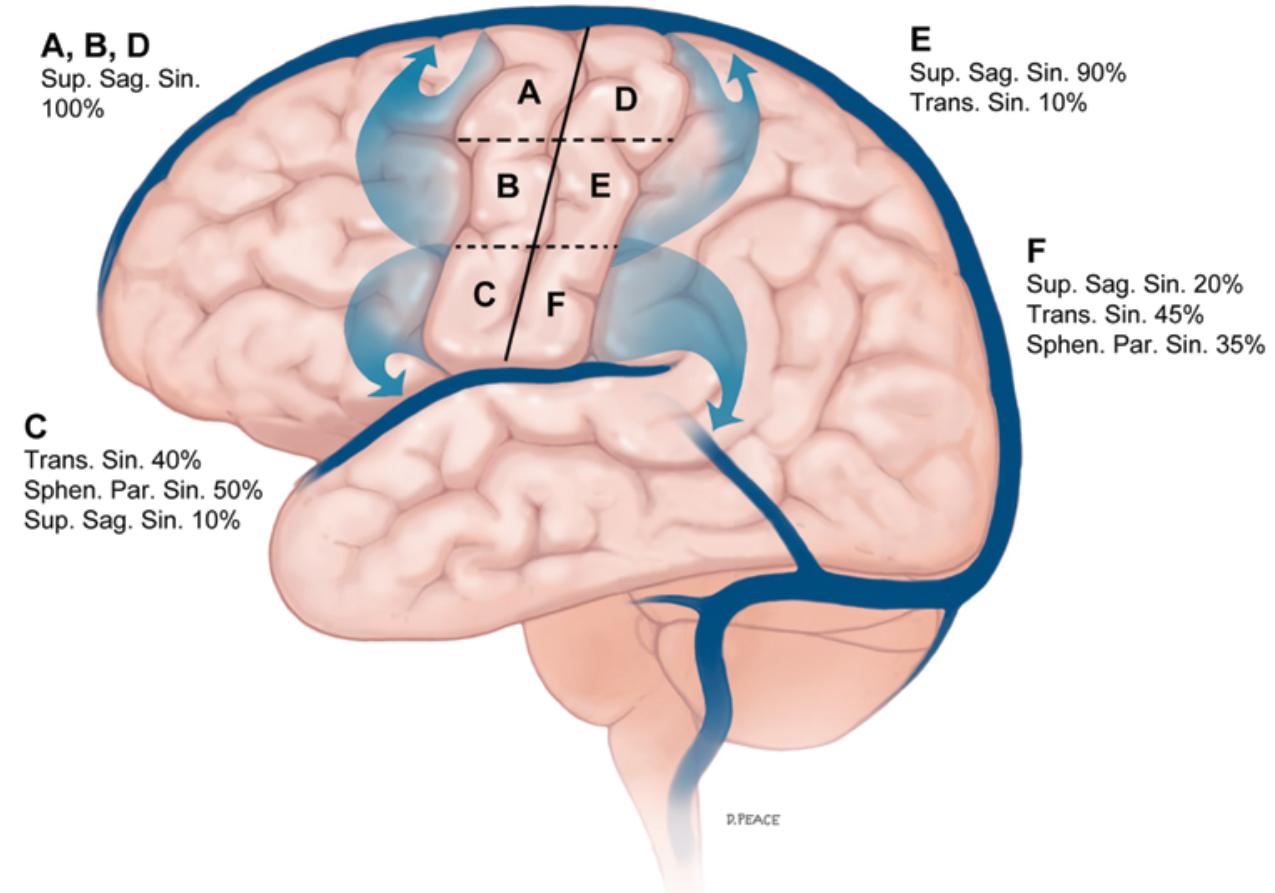

FIG. 8. Dominant drainage pathways of different parts of the central lobe. $A, B$, and $C$ are respectively the upper, middle, and lower thirds of the precentral gyrus, and $D, E$, and $F$ are the upper, middle, and lower thirds of the postcentral gyrus. Parts $A, B$, and $D$ drain to the superior sagittal sinus in $100 \%$ of the hemispheres. Parts $C$ and $F$ drain predominantly to the sphenoparietal and transverse sinuses with a slightly higher proportion of the precentral gyrus draining to the sphenoparietal and the postcentral gyrus to the transverse sinus. In some hemispheres the lower third drained to the superior sagittal sinus due to the presence of a large vein of Trolard that drained predominantly upwards. The most common location of the vein of Trolard was along the territory drained by the postcentral vein. In $10 \%$ of the hemispheres, area $E$ drained to the transverse sinus due to the presence of larger than average parietosylvian veins. Sin. = sinus; Sphen. Par. = sphenoparietal; Trans. = transverse. Copyright Albert L. Rhoton Jr. Published with permission.

the paracentral vein to the superior sagittal sinus. The area drained by this vein covers the anterior half and the anterior two-thirds of the posterior half. The posterior margin and the posterior half of the inferior margin of the paracentral lobule drained through the anteromedial parietal vein, which emptied into the superior sagittal sinus.

\section{Lateral Surface}

The superior third drained mainly upward through the central vein to the superior sagittal sinus. The postcentral vein commonly drained the posterior margin of the postcentral gyrus (Fig. 8). The middle third drained predominantly to the superior sagittal sinus through the central vein. However, the anterior and posterior margins of the central lobe were drained by the pre- and postcentral veins, respectively. The precentral veins curved anteriorly as they ascended and thus frequently did not contribute to the drainage of the superior third of the central lobe. At the junction between the middle and inferior third, there was usually a change in the drainage direction. The inferior third drained downward to empty into the superficial sylvian veins and from there to the transverse sinus (via vein of Labbé) or to the sphenoparietal sinus (via the superficial sylvian veins). The frontosylvian veins drained the precentral gyrus and the parietosylvian veins drained the postcentral gyrus.

\section{Discussion}

Advances in microsurgical techniques, modern neuroimaging, neuronavigation systems, and cortical mapping have made surgery in the central lobe safer. However, knowledge of the anatomy remains an essential tool for performing safe and accurate approaches to the central lobe.

\section{Craniometric Features}

Broca $^{10,11}$ was the first to describe the relationship of the coronal suture with the central sulcus in 1861 and was the first to perform a craniotomy oriented by cranial topography. The coronal suture is easily palpable through the scalp and provides valuable information, as seen on CT and MR images, that is easily transferable to the surgical field.

The coronal suture and central lobe have a fairly constant relationship. They run somewhat parallel, but the separation between the coronal suture and the precentral gyrus is less pronounced at their lower end than at their upper end bordering the superior sagittal sinus..$^{10,11,17,21-23,40,46}$ However, the closest point between the coronal suture and the precentral and central sulci was found to be the point at or near where the superior temporal line crosses the coronal suture. 


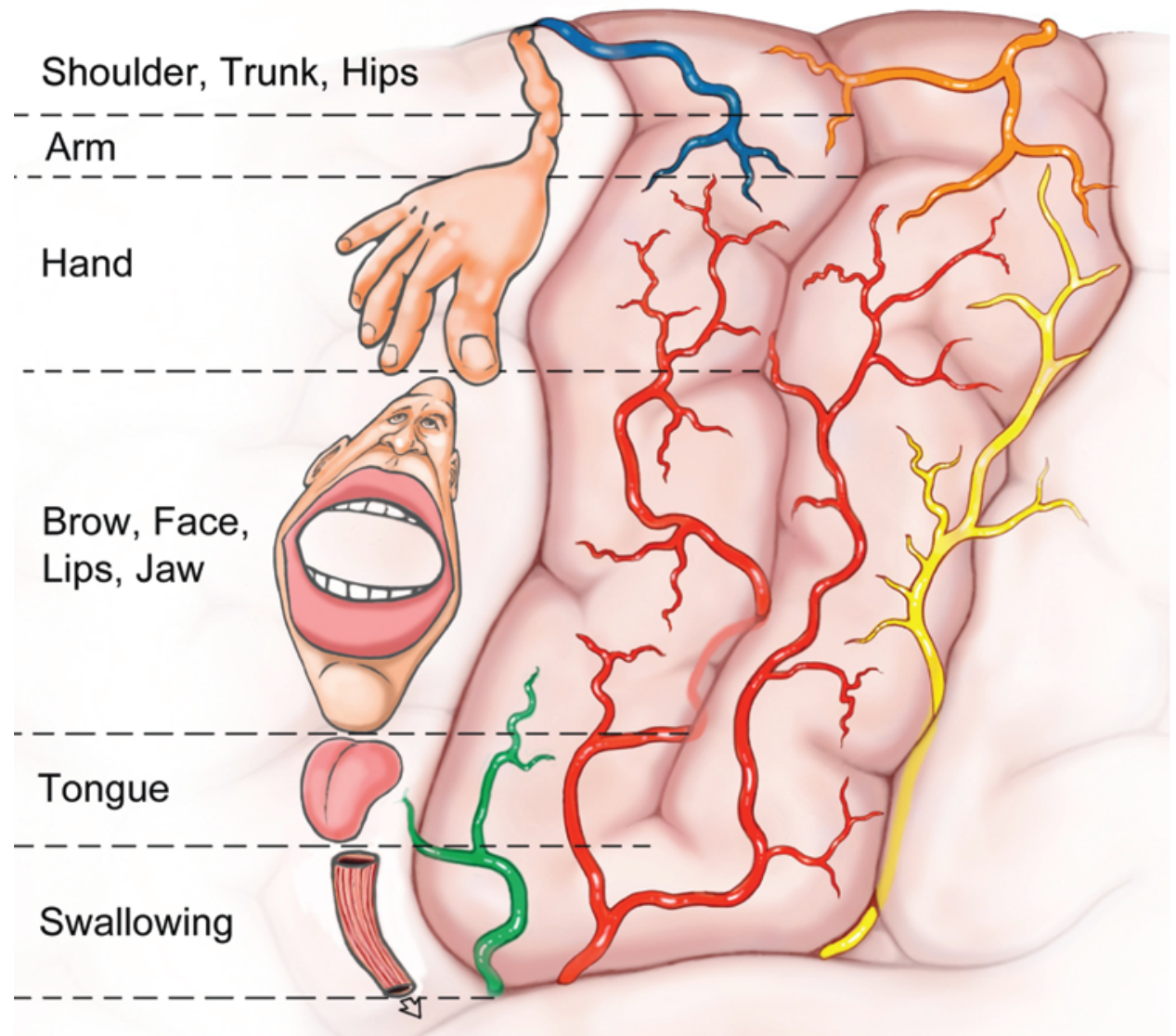

FIG. 9. Diagram of the left hemisphere showing the correlation of the most common pattern of central lobe arterial supply to the classic homunculus on the lateral surface. The cortical areas supporting fine movements are disproportionally large in comparison with areas supporting more gross movements. Obliteration of a single arterial branch may lead to a motor or sensory deficit in a specific part of the body. See Fig. 5 for legend for arteries on pre- and postcentral gyri. Copyright Albert L. Rhoton Jr. Published with permission.

\section{Neural Features}

Although there is considerable variability in sulcal and gyral anatomy surrounding the central lobe, close inspection reveals a relatively constant basic organization. The development of refined microsurgical techniques such as transsulcal approaches established the sulci and gyri as fundamental landmarks of the cerebrum. ${ }^{45}$ The cortex of the central lobe has very specific functional localization. Therefore, it is essential to correctly identify sulci and gyri on preoperative imaging studies when operating in the region and to understand that lesions causing significant mass effect may distort normal topography and landmarks. Recent studies have shown that a greater extension of glioma resection is a statistically significant predictor of progression-free survival and length of survival. $5,8,13,15,16,25,27,30-32,34,35,47-49$ Therefore, radical resection should be pursued but not at the expense of patients' quality of life. This strategy minimizes the risk of misdiagnosis, relieves the symptoms of mass effect, and can improve neurological deficits due to compression of the central lobe. To accomplish this, an understanding of gyral and sulcal anatomy is essential. Currently, eloquent sensorimotor cortex identification based on topographical and ra- diological anatomy is combined with functional MRI and direct electrical cortical stimulation. ${ }^{6,18,26,29,33,37,50,55}$

The authors of several studies on mapping the sensorimotor cortex have reported that despite having a common general organization, variations in the somatotopy are frequently found. $2,67,18,26,29,33,37,38,52,53,55$ They suggest that Penfield's homunculus be used as a simplified teaching tool but not as an accurate map (Fig. 9).2,18,38,52,53 Two groups have reported sensorimotor function outside the central lobe..$^{5,55}$ These studies suggested that the primary motor cortex may extend beyond the anterior edge of the precentral gyrus. Berger and Hadjipanayis ${ }^{5}$ found that the lowest threshold for electrical stimulation-induced movements of the body was on the precentral gyrus. When stimulating the premotor cortex, the threshold was higher, and the movements were slower and likely to involve larger groups of muscles. These findings may explain the transient motor deficits reported following resection of the area anterior to the precentral gyrus.

Berger and colleagues s,13,27,48,49 have also reported on the importance of cortical mapping to delineate the motor cortex to achieve the greatest resection possible and to improve the prognosis in glioma surgery. Robles and 
colleagues $^{47}$ reported that radical resection of low-grade gliomas without preserving any margin around eloquent structures, such as the precentral gyrus, can be safely performed using subpial excision up to the edge of the arachnoid covering the adjacent eloquent gyrus. Martino et al. ${ }^{30}$ demonstrated that radical glioma resections in eloquent areas of the brain, despite causing transient deficits in the immediate postoperative period, were associated with a decrease in morbidity over medium- and long-term periods and a longer preservation of the patient's professional life. Chang et al. ${ }^{14}$ reported approaching cavernous malformations deep to the precentral gyrus obliquely through the premotor cortex while avoiding damage to cortical arteries. An understanding of sulcal, gyral, and arterial anatomy is essential to perform these resections safely and accurately.

\section{Arterial Supply}

When operating in the central lobe, it is important to remain constantly aware of the position of the arterial supply because of the severe deficits that may follow their occlusion. Gempt et al. ${ }^{20}$ reported that neurological impairment following glioma resection was more frequently due to ischemic lesions than to cortical or subcortical structural damage. When performing surgeries involving the medial surface of the frontal lobe, care must be taken to avoid coagulating posteriorly directed branches of the pericallosal and callosomarginal arteries. Coagulation of these branches, although at a distance from the central lobe, may lead to motor weakness more prominent in the contralateral foot and leg than in the upper limb. Sensory loss, usually transient, is another consequence of infarctions of the supplementary motor area. Urinary incontinence occurs in the acute phase after bilateral occlusion.

Chaddad-Neto et al. ${ }^{12}$ reported that arteriovenous malformations (AVMs) of the central lobe are suitable for surgical treatment in selected cases based on neurological status, AVM grade, patient age, and so on. The first steps are to open all the sulci adjacent to the lesion and to identify and differentiate the feeding arteries from arterialized veins. If this differentiation is not sufficient with the microscope, temporary clipping may help. If temporarily clipped, a feeding artery will collapse between the clip and the nidus, and an arterialized vein will tumesce between the clip and the nidus. AVMs of the central lobe on the lateral surface usually receive feeders from the $\mathrm{M}_{4}$ cortical branches. It is important to be sure that the artery being obliterated ends in the AVM and is not a "passing through" artery that supplies brain tissue distal to the AVM, while remembering that "passing through" arteries may feed the AVM through small lateral branches that must be carefully dissected and obliterated while preserving the main arterial trunk. ${ }^{3}$ AVMs on the medial surface receive feeders from branches of the ACA. AVMs adjacent to the superior border will, most likely, receive feeders from both the MCA and the ACA. After obliteration of the AVM's feeders, circumferential dissection of the nidus and transection of the draining veins is then performed.

\section{Venous Drainage}

Sacrifice of individual cortical veins does not usually lead to venous infarction, brain swelling, hemorrhage, or neurological deficits because of the abundant anastomoses between veins draining adjacent cortical areas. There are also anastomoses at the superior border of the hemispheres between the veins draining adjacent parts of the lateral and medial surface of the central lobe. These anastomoses are located at the terminal ends of the veins just proximal to where the bridging veins enter the superior sagittal sinus. However, the sacrifice of a major venous trunk should be avoided, either by working around it or dividing some smaller tributaries that will allow the major trunk to be displaced out of the surgical field. Care should be taken to avoid damage to bridging veins if they appear larger than normal, because the risk of venous infarction increases as the veins increase in size. In some cases a large vein of Trolard will drain the majority of the central lobe. Obliteration of such a vein can lead to venous infarction with severe deficits. As a result of the arterial supply to the infarcted tissue not being compromised, capillary hypertension and hemorrhagic transformation is common and is typically heterogeneous and gyriform.

When operating in the parasagittal area, an attempt must be made to preserve the sinuses coursing in the dura lateral to the superior sagittal sinus, which frequently receives the terminal end of several cortical veins before emptying into the superior sagittal sinus. Obliteration of the bridging veins from the central lobe that empty into the superior sagittal sinus may cause contralateral hemiparesis more prominent in the lower limbs and usually transient. ${ }^{39}$

\section{Conclusions}

Despite some variability, there are common patterns in gyral and sulcal configuration, craniometric relationships, arterial supply, and venous drainage that can create a road map for approaching pathologies in the central lobe.

\section{Acknowledgments}

We would like to express our gratitude to Robin Barry and David Peace for their assistance with the illustrations and to Jessica Striley for her editorial assistance.

\section{References}

1. Alves RV, Ribas GC, Párraga RG, de Oliveira E: The occipital lobe convexity sulci and gyri. J Neurosurg 116:10141023, 2012

2. Barinaga M: Remapping the motor cortex. Science 268:1696-1698, 1995

3. Baskaya MK, Jea A, Heros RC, Javahary R, Sultan A: Cerebral arteriovenous malformations. Clin Neurosurg 53:114144, 2006

4. Becker RF: The cerebral cortex of man. By Wilder Penfield and Theodore Rasmussen. The Macmillan Company, New York, N.Y. 1950. 248 pp. Am J Phys Anthropol 11:441-444, 1953

5. Berger MS, Hadjipanayis CG: Surgery of intrinsic cerebral tumors. Neurosurgery 61 (1 Suppl):279-305, 2007

6. Bittar RG, Olivier A, Sadikot AF, Andermann F, Pike GB, Reutens DC: Presurgical motor and somatosensory cortex mapping with functional magnetic resonance imaging and positron emission tomography. J Neurosurg 91:915-921, 1999

7. Bittar RG, Olivier A, Sadikot AF, Andermann F, Reutens 
DC: Cortical motor and somatosensory representation: effect of cerebral lesions. J Neurosurg 92:242-248, 2000

8. Bloch O, Han SJ, Cha S, Sun MZ, Aghi MK, McDermott $\mathrm{MW}$, et al: Impact of extent of resection for recurrent glioblastoma on overall survival. Clinical article. J Neurosurg 117:1032-1038, 2012

9. Boling WW, Olivier A: Localization of hand sensory function to the pli de passage moyen of Broca. J Neurosurg 101:278-283, 2004

10. Broca P: Instructions Craniologiques et Craniométriques de la Société d'Anthropologie de Paris. Paris: G Masson, 1875

11. Broca P: Sur la topographie crânio-cérébrale ou sur les rapports anatomiques du crâne et du cerveau. Rev Anthropol 5:193-244, 1876

12. Chaddad-Neto F, Joaquim AF, dos Santos MJ, Linhares PW, de Oliveira E: Microsurgical approach of arteriovenous malformations in the central lobule. Arq Neuropsiquiatr 66:872-875, 2008

13. Chang EF, Clark A, Smith JS, Polley MY, Chang SM, Barbaro NM, et al: Functional mapping-guided resection of low-grade gliomas in eloquent areas of the brain: improvement of long-term survival. Clinical article. J Neurosurg 114:566-573, 2011

14. Chang EF, Gabriel RA, Potts MB, Berger MS, Lawton MT: Supratentorial cavernous malformations in eloquent and deep locations: surgical approaches and outcomes. Clinical article. J Neurosurg 114:814-827, 2011

15. Duffau H: Contribution of cortical and subcortical electrostimulation in brain glioma surgery: methodological and functional considerations. Neurophysiol Clin 37:373-382, 2007

16. Duffau H, Capelle L, Denvil D, Sichez N, Gatignol P, Taillandier L, et al: Usefulness of intraoperative electrical subcortical mapping during surgery for low-grade gliomas located within eloquent brain regions: functional results in a consecutive series of 103 patients. J Neurosurg 98:764-778, 2003

17. Ebeling U, Rikli D, Huber P, Reulen HJ: The coronal suture, a useful bony landmark in neurosurgery? Craniocerebral topography between bony landmarks on the skull and the brain. Acta Neurochir (Wien) 89:130-134, 1987

18. Farrell DF, Burbank N, Lettich E, Ojemann GA: Individual variation in human motor-sensory (rolandic) cortex. J Clin Neurophysiol 24:286-293, 2007

19. Fernández-Miranda JC, Rhoton AL Jr, Alvarez-Linera J, Kakizawa Y, Choi C, de Oliveira EP: Three-dimensional microsurgical and tractographic anatomy of the white matter of the human brain. Neurosurgery 62 (6 Suppl 3):989-1028, 2008

20. Gempt J, Krieg SM, Hüttinger S, Buchmann N, Ryang YM, Shiban E, et al: Postoperative ischemic changes after glioma resection identified by diffusion-weighted magnetic resonance imaging and their association with intraoperative motor evoked potentials. J Neurosurg 119:829-836, 2013

21. Gusmão S, Reis C, Silveira RL, Cabral G: [Relationships between the coronal suture and the sulci of the lateral convexity of the frontal lobe: neurosurgical applications.] Arq Neuropsiquiatr 59 (3-A):570-576, 2001 (Portugese)

22. Gusmão S, Ribas GC, Silveira RL, Tazinaffo U: [The sulci and gyri localization of the brain superolateral surface in computed tomography and magnetic resonance imaging.] Arq Neuropsiquiatr 59:65-70, 2001 (Fr)

23. Gusmão S, Silveira RL, Arantes A: [Landmarks to the cranial approaches.] Arq Neuropsiquiatr 61 (2A):305-308, 2003 (Portuguese)

24. Harkey HL, al-Mefty O, Haines DE, Smith RR: The surgical anatomy of the cerebral sulci. Neurosurgery 24:651-654, 1989
25. Ius T, Isola M, Budai R, Pauletto G, Tomasino B, Fadiga L, et al: Low-grade glioma surgery in eloquent areas: volumetric analysis of extent of resection and its impact on overall survival. A single-institution experience in 190 patients. Clinical article. J Neurosurg 117:1039-1052, 2012

26. Jeong JW, Asano E, Brown EC, Tiwari VN, Chugani DC, Chugani HT: Automatic detection of primary motor areas using diffusion MRI tractography: comparison with functional MRI and electrical stimulation mapping. Epilepsia 54:1381-1390, 2013

27. Keles GE, Lundin DA, Lamborn KR, Chang EF, Ojemann G, Berger MS: Intraoperative subcortical stimulation mapping for hemispherical perirolandic gliomas located within or adjacent to the descending motor pathways: evaluation of morbidity and assessment of functional outcome in 294 patients. J Neurosurg 100:369-375, 2004

28. Kendir S, Acar HI, Comert A, Ozdemir M, Kahilogullari G, Elhan A, et al: Window anatomy for neurosurgical approaches. Laboratory investigation. J Neurosurg 111:365-370, 2009

29. Lehéricy S, Duffau H, Cornu P, Capelle L, Pidoux B, Carpentier A, et al: Correspondence between functional magnetic resonance imaging somatotopy and individual brain anatomy of the central region: comparison with intraoperative stimulation in patients with brain tumors. J Neurosurg 92:589-598, 2000

30. Martino J, Gomez E, Bilbao JL, Dueñas JC, Vázquez-Barquero A: Cost-utility of maximal safe resection of WHO grade II gliomas within eloquent areas. Acta Neurochir (Wien) 155:41-50, 2013

31. McGirt MJ, Chaichana KL, Attenello FJ, Weingart JD, Than $\mathrm{K}$, Burger PC, et al: Extent of surgical resection is independently associated with survival in patients with hemispheric infiltrating low-grade gliomas. Neurosurgery 63:700-708, 2008

32. McGirt MJ, Chaichana KL, Gathinji M, Attenello FJ, Than $\mathrm{K}$, Olivi A, et al: Independent association of extent of resection with survival in patients with malignant brain astrocytoma. J Neurosurg 110:156-162, 2009

33. Nii Y, Uematsu S, Lesser RP, Gordon B: Does the central sulcus divide motor and sensory functions? Cortical mapping of human hand areas as revealed by electrical stimulation through subdural grid electrodes. Neurology 46:360-367, 1996

34. Orina JN, Fang S, Meyer FB, Parney IF: Surgical outcomes in a modern series of low-grade gliomas undergoing surgical resection. Neurosurgery 60:156-157, 2013 (Abstract)

35. Orringer D, Lau D, Khatri S, Zamora-Berridi GJ, Zhang K, Wu C, et al: Extent of resection in patients with glioblastoma: limiting factors, perception of resectability, and effect on survival. J Neurosurg 117:851-859, 2012

36. Penfield W, Boldrey E: Somatic motor and sensory representation in the cerebral cortex of man as studied by electrical stimulation. Brain 60:389-443, 1937

37. Pujol J, Deus J, Acebes JJ, Villanueva A, Aparicio A, Soriano-Mas C, et al: Identification of the sensorimotor cortex with functional MRI: frequency and actual contribution in a neurosurgical context. J Neuroimaging 18:28-33, 2008

38. Rao SM, Binder JR, Hammeke TA, Bandettini PA, Bobholz JA, Frost JA, et al: Somatotopic mapping of the human primary motor cortex with functional magnetic resonance imaging. Neurology 45:919-924, 1995

39. Rhoton AL Jr: The cerebral veins. Neurosurgery 51 (4 Suppl):S159-S205, 2002

40. Rhoton AL Jr: The cerebrum. Anatomy. Neurosurgery 61 (1 Suppl):37-119, 2007

41. Rhoton AJ: General and micro-operative techniques, in Youmans JR (ed): Neurological Surgery, ed 4. Philadelphia: WB Saunders, 1996, Vol 2, pp 724-766 
42. Rhoton AL Jr: The lateral and third ventricles. Neurosurgery 51 (4 Suppl):S207-S271, 2002

43. Rhoton AL Jr: Rhoton's Cranial Anatomy and Surgical Approaches. Philadelphia: Lippincott Williams \& Wilkins, 2003

44. Rhoton AL Jr: The supratentorial arteries. Neurosurgery 51 (4 Suppl):S53-S120, 2002

45. Ribas GC: The cerebral sulci and gyri. Neurosurg Focus 28(2):E2, 2010

46. Ribas GC, Yasuda A, Ribas EC, Nishikuni K, Rodrigues AJ Jr: Surgical anatomy of microneurosurgical sulcal key points. Neurosurgery 59 (4 Suppl 2):ONS177-ONS211, 2006

47. Robles SG, Gatignol P, Lehéricy S, Duffau H: Long-term brain plasticity allowing a multistage surgical approach to World Health Organization Grade II gliomas in eloquent areas. J Neurosurg 109:615-624, 2008

48. Sanai N, Berger MS: Intraoperative stimulation techniques for functional pathway preservation and glioma resection. Neurosurg Focus 28(2):E1, 2010

49. Sanai N, Berger MS: Operative techniques for gliomas and the value of extent of resection. Neurotherapeutics 6:478486, 2009

50. Sanchez-Panchuelo RM, Francis S, Bowtell R, Schluppeck D: Mapping human somatosensory cortex in individual subjects with 7T functional MRI. J Neurophysiol 103:2544-2556, 2010

51. Sarmento SA, Jácome DC, de Andrade EM, Melo AV, de Oliveira OR, Tedeschi H: Relationship between the coronal suture and the central lobe: how important is it and how can we use it in surgical planning? Arq Neuropsiquiatr 66:868871,2008

52. Schott GD: Penfield's homunculus: a note on cerebral cartography. J Neurol Neurosurg Psychiatry 56:329-333, 1993

53. Sutherling WW, Crandall PH, Darcey TM, Becker DP, Levesque MF, Barth DS: The magnetic and electric fields agree with intracranial localizations of somatosensory cortex. Neurology 38:1705-1714, 1988

54. Tanriover N, Rhoton AL Jr, Kawashima M, Ulm AJ, Yasuda
A: Microsurgical anatomy of the insula and the sylvian fissure. J Neurosurg 100:891-922, 2004

55. Uematsu S, Lesser R, Fisher RS, Gordon B, Hara K, Krauss GL, et al: Motor and sensory cortex in humans: topography studied with chronic subdural stimulation. Neurosurgery 31:59-72, 1992

56. Ugur HC, Kahilogullari G, Coscarella E, Unlu A, Tekdemir I, Morcos JJ, et al: Arterial vascularization of primary motor cortex (precentral gyrus). Surg Neurol 64 (Suppl 2):S48S52, 2005

57. Wen HT, Rhoton AL Jr, de Oliveira E, Cardoso AC, Tedeschi $\mathrm{H}$, Baccanelli M, et al: Microsurgical anatomy of the temporal lobe: part 1: mesial temporal lobe anatomy and its vascular relationships as applied to amygdalohippocampectomy. Neurosurgery 45:549-592, 1999

58. Yousry TA, Schmid UD, Jassoy AG, Schmidt D, Eisner WE, Reulen HJ, et al: Topography of the cortical motor hand area: prospective study with functional MR imaging and direct motor mapping at surgery. Radiology 195:23-29, 1995

\section{Author Contributions}

Conception and design: Rhoton, Frigeri, Paglioli. Acquisition of data: Rhoton, Frigeri, Paglioli. Analysis and interpretation of data: Rhoton, Frigeri. Drafting the article: Rhoton, Frigeri. Critically revising the article: Rhoton, Frigeri, Paglioli. Reviewed submitted version of manuscript: Rhoton, Frigeri, Paglioli. Approved the final version of the manuscript on behalf of all authors: Rhoton. Statistical analysis: Rhoton, Frigeri. Administrative/technical/material support: Rhoton. Study supervision: Rhoton. Provided training in microsurgical anatomy: de Oliveira.

\section{Correspondence}

Albert L. Rhoton Jr., Department of Neurological Surgery, University of Florida, P.O. Box 100265, Gainesville, FL 32610. email: rhoton@neurosurgery.ufl.edu. 